\title{
Analysis on Application of Big Data in Intelligent Tourism
}

\author{
Gangzhi Guo \\ School of Culture and Tourism, Yiwu Industrial and Commercial College, Yiwu Zhejiang, \\ 322000, China
}

Key words: Big data, Intelligent tourism.

\begin{abstract}
Big data, Internet of Things and cloud computing technology develop like a raging fire. Each industry is looking for the strategy to apply big data in industrial development. Traditional tourism industry also pays attention to application of big data technology in the process of intelligent tourism transformation. Guiding Idea on Promoting Development of Intelligent Tourism issued by National Tourism Administration in 2015 indicates that modern tourism should implement ticket appointment system, predict the crowdedness degree of scenic spot and improve tourist comfort level evaluation requirement. With ticket appointment system, administrative department of scenic spot can know future flow rate of visitors in the scenic spot in advance, process collected data information, accurately predict crowdedness degree of scenic spot, and formulate reasonable decisions, which contributes to improving tourist comfort level. To achieve these objectives, massive data should be analyzed and processed. Thus, the application of big data in tourism industry is a general trend.
\end{abstract}

\section{Introduction}

Tourism industry greatly depends on information. Tourism operators need to adjust operation strategy in time according to the signal of information transmission, improve tourist comfort level, attract tourists and gain profits. Consumers need to arrange the schedule according to accurate tourism information, save preparation time and improve travelling convenience. In recent years, computer technology and information technology have developed rapidly, which generates significant influence on tourism industry, such as electronic management of scenic spot and hotel food service industry. The development of numerous tourism websites also offers rich information resources for consumers, improves the problem of seriously unequal supply and demand information in the tourism industry and helps consumers get better tourism services. However, the application of information technology and computer technology should not stop here. Big data technology should be used to promote transformation to intelligent tourism to traditional tourism industry and facilitate further development of tourism cause.

\section{Rise of intelligent tourism}

Guiding Idea on Promoting Development of Intelligent Tourism issued by National Tourism Administration in 2015 triggers the tide of studying intelligent tourism ${ }^{[1]}$. This paper will introduce the concept of intelligent tourism, core content and development process. Intelligent tourism means the information about scenic spot resources, itinerary, hotel food service is gathered and integrated by cloud computing technology and big data processing means as well as developed computer network and popular network equipment so that consumers can effectively utilize the information during making the travelling plan. Meanwhile, operators of tourism industry apply advanced information collection and processing technology to adjust operation strategy in time, pursue personalized tourist customization service and improve tourist satisfaction and service quality of tourism industry. 
The core of tourism industry is service. Even if traditional tourism industry is transforming to intelligent tourism, the core content of tourism - service cannot be ignored ${ }^{[2]}$. Thus, all technologies are just means and cannot influence the service quality. The means adopted by intelligent tourism aim to better offer services. After this is ensured, the core technology to be applied can be discussed. The technology of intelligent tourism is infrastructure of tourism industry. cloud computing, cloud computing, high-speed wireless communication, geographic information system and virtual reality technology are combined with practical features of tourism industry to research and develop the technology with strong operability suitable for development features of tourism industry, which is the most important work of intelligent tourism workers.

\section{Big data}

The rise of big data study results from massive data generated in modern production and life. Explosive information growth makes existing data processing software unable to collect, sort, process and analyze data efficiently, which leads to information waste and even error and affects enterprise operators to make scientific and effective decisions according to the information. Hence, big data rise ${ }^{[3]}$. Big data are not a technology. Actually, big data belong to a kind of phenomenon which appears due to information explosion in modern society. Intelligent tourism will apply big data processing technology which appears together with big data phenomenon. Data workers research and develop non-mainstream data processing software to process massive structured, semi-structured and even non-structured data, mine the rules of massive data and combine with actual conditions to predict future development.

\section{Combination of big data with intelligent tourism}

As electronization of scenic spot management and informatization of hotel food service industry develop continuously, the data of tourism industry are also accumulated rapidly. The most valuable information of tourism industry hide in these massive data. Thus, big data processing technology is required to analyze and process massive data so as to mine valuable information.

\section{Application strategy}

The development objective of intelligent tourism is to construct a public service platform based on massive information by stages and offer superior services foe customers through taking the platform as the carrier. On this basis, tourists are guided to form the behavior pattern suitable for network, transform enterprise operation and management strategy and improve the value of enterprises an consumers under the background of intelligent tourism.

\section{Expansion from inside to outside}

"Big tourism" should be carried out step by step in the development process of intelligent tourism. In the initial stage, information collection, processing and analysis are mainly used in the tourism industry. Based on internal practice experience, the application of big data should be expanded to the outside to make the gap between tourism industry and other external industries disappear and establish communication between tourism industry and external industries. The combination of tourism industry with external industry can be conducted by referring to the following mode: real-time road traffic situation issued by the traffic development can help tourists adjust traffic route, and avoid time consumption. Besides, smooth traffic can improve tourists' psychological comfort level. Weather information issued by meteorological department can play a similar role. tourism industry establishes favorable communication tourism industry with traffic development and meteorological department, collect and offer traffic and weather information for tourists, which can help enterprises in tourisms industry boost service quality and enhance consumers' satisfaction with enterprises and improve the meteorological department of tourism enterprises. On the other hand, 
intelligent tourism must cooperate with mobile and Unicom operators, utilize high-speed wireless communication technology and unite web portals such as Tuniu, Qunar.com, Ctrip to promote information sharing of tourism enterprises. Through the information about scenic spot introduction, traffic route, weather information and ticket price which is collected on tourism websites and concerned by consumers, tourists can make travelling plans more conveniently. In addition, potential consumers' consumption enthusiasm will be stimulated to boost business volume of tourism industry. Consumers' use of various websites also provides sources for massive data needed by intelligent tourism and lays a foundation for further data analysis.

\section{Expansion from part to all}

The transformation of traditional tourism to intelligent tourism is a long-term and sustainable process. It will take time for the linkage of each industry. It also will take a long time to gradually popularize the idea of intelligent tourism in each region ${ }^{[4]}$. Since China is vast in territory, economic development degree of each region and popularization degree of computer technology differ a lot in each region. In the eastern cities with good economic development and technical progress, the concept of intelligent tourism has been generally accepted by tourism enterprises. Hence, the transformation of tourism industry will be relatively easy. After the policy about intelligent tourism is issued, it will also be promoted and implemented efficiently. But, economic development degree in other regions fall behind, and local development of cloud computing, Internet of Things and big data processing technology lags. Besides, there are short of professional and technical personnel as well as management personnel with advanced idea. Thus, the transformation of intelligent tourism is also faced with many barriers. On the one hand, the cognition degree and acceptance degree of tourism enterprises and consumers for intelligent tourism and relevant technologies are very low, which hinders promotion of intelligent tourism idea. Meanwhile, due to the scarcity of technical personnel, even if enterprises realize the importance of intelligent tourism and big data processing technology, they are confronted with technical barriers. Thus, the transformation of tourism industry cannot be accomplished in an action. If China seeks quick success in promoting the application of big data technology in tourism industry may cause the behindhand regions follow suit blindly and damage local tourism system. Intelligent tourism based on big data should be gradually expanded from point to plane. First of all, it should be carried out in the regions with high economic development degree and advanced technology to accumulate practical experience. Then, the technology should be first developed in other regions to train management talents of intelligent tourism and technical talents of big data processing. Based on construction experience of pilot region, intelligent tourism should be promoted in other regions.

\section{Construction of data center}

Big data construction of intelligent tourism needs local standards for data catalogue, exchange and sharing to standardize data center construction of tourist administration in each region. Data information content involved in traditional tourism is single, and information size is small, so it is easy to process the information. However, intelligent tourism requires very huge quantity of information, and information contents and types involved far exceed traditional tourism ${ }^{[5]}$. Therefore, original data catalogue standard cannot meet development requirements of intelligent tourism. It is necessary to combine development trend of intelligent tourism and consumers' information demand to update and revise data catalogue standard as well as cover existing information data scope. Standard data catalogue can facilitate efficient information collection. Meanwhile, the relevancy of various data can be shown clearly through standard data catalogue. This simplified data analysis process and significantly reduces data analysis error.

\section{Standardization of information sharing norms}

The ultimate purpose of intelligent tourism to utilize information technology and network technology is to transfer the effective information to tourism enterprises and consumers, and offer more superior tourism services. Tourism industry depends on information to a large extent. The information sources 
are also very wide. The types of information collected by each region. Each tourism enterprise and each website differ. The information cannot be shared conveniently to give play to greater value of information collected. Thus, intelligent tourism should establish standard information sharing norms in order to better utilize massive data. Enterprises can gain more comprehensive information through sharing and then predict customers' features and preferences more accurately. In this way, enterprises can recommend more personalized and more attractive tourist products for potential consumers. Tourist attractions may depend on shared information to fully master visitor flow rate in future period so that management department can arrange security work and visitor evacuation according to actual conditions so as to make sure tourist safety and orderly scenic spot management. Online tourism websites depend on their own information accumulation and shared information of scenic spots or hotel food service industry to predict tourism preference and tourism peak of local consumers so that they can arrange targeted tour routes and attract more potential consumers.

\section{Software development support}

Only collection of massive data is of no significance for the development of intelligent tourism. The most important point of big data strategy is to process and mine valuable information for tourism industry ${ }^{[6]}$. Thus, tourism enterprises must research and develop software system used to process big data first and offer support for development of tourism industry in order to develop intelligent tourism which depends on big data.

To research and develop software system, data analysis model should be established first. The service objects of tourism industry have six important activity elements: food, accommodation, traffic, sightseeing. Shopping and entertainment. Thus, the data analysis mode established should be based on the six elements. It is required to establish multi-dimensional analysis model which expands crosswise and lengthways according to actual conditions and features of tourism industry in each region and conduct analysis, calculation and prediction according to the collected and shared data.

\section{Excavation of commercial value of information}

With complete data center, standard sharing mechanism and advanced software support, tourism enterprises need not worry about information sources. The next task is to mine valuable information for enterprise operation and tourism development from massive data. Consumers' consumption preference and behavior pattern can be confirmed through seeking consumers' behavior characteristic law hidden in big data of tourism industry with data mining ${ }^{[7]}$. Then, when consumers search relevant tourism information, tourism enterprises can give customers personalized recommendation according to customers' behavior characteristics mined to improve their tourism interest and promote development of tourism industry. For example, customers also search the information about five-star hotels bear the scenic spot while searching the information about the scenic spot. This indicates customers pay attention to tourism quality. In combination of age and gender information of the tourist, the consumption level and tourism preference of this tourist can be confirmed. Then, the enterprise can recommend the food and hotel services with high consumption level and high-end service quality. During recommending the tour route for the consumer, the tour route which involves high consumption level and high service level can be recommend. In this way, enterprise operation and development of tourism industry are promoted.

\section{Conclusion}

Through policy guidance of government sector, intelligent tourism has started to attract the attention of tourism enterprises. More and more online tourism companies spring up. However, the application of big data in tourism industry is also in the initial state. Since tourism industry depends on information to a large extent, the application of big data technology in the industry is a strategy which must be implemented. The whole industry needs to carry out scientific and deep research on the strategy of combining big data with tourism industry, to expand pure online application to offline application, to collect tourism information, to utilize advanced analysis software to mine valuable 
information for tourism enterprises and consumers and to help tourism enterprises offer more fast and superior services for tourists.

\section{References}

[1] Weng Kai, Study on application of big data in intelligent tourism, Technology Innovation and Application, 2015,No.13624:87-88.

[2] Liu Peng, Analysis of "intelligent tourism" development under the era of electronic mobile network and big data, Modern Communication, 2015,No.41810:31.

[3] Laing Changyong, Ma Yinchao, Lu Caihong, Big data mining: core of intelligent tourism, Research On Development, 2015,No.18005:134-139.

[4] Chen Haidi, Study on application of big data in intelligent tourism, Contemporary Economics, 2015,No.38929:38-39.

[5] Luo Chengkui, Application of big data in intelligent tourism, Tourism Overview (II), 2013,08:59-60.

[6] Wu Maoying, Huang Keji, Net-nography comment: application and innovation in the era of intelligent tourism, Tourism Tribune, 2014,v.29;No.22012:66-74.

[7] Chen Tao, Li Jiao, Study on tourism service supply chain management based on big data, E-government Affairs, 2013,No.13212:32-40. 